\title{
Multiobjective Decision-Making in Integrated Water Management
}

\author{
I. H. M. Pouwels ${ }^{1}$, H. G. Wind ${ }^{1}$ and V. J. Witter ${ }^{2}$ \\ 1 University of Twente, Department of Civil Engineering and Management, P.O. Box 217, \\ 7500 AE Enschede, The Netherlands \\ 2 Water Authority West-Brabant, P.O. Box 2212, 4800 CE Breda, The Netherlands
}

\begin{abstract}
Traditionally, decision-making by water authorities in the Netherlands is largely based on intuition. Their tasks were, after all, relatively few and straight-forward. The growing number of tasks, together with the new integrated approach on water management issues, however, induces water authorities to rationalise their decision process. In order to choose the most effective water management measures, the external effects of these measures need to be taken into account. Therefore, methods have been developed to incorporate these effects in the decision-making phase. Using analytical evaluation methods, the effects of various measures on the water system (physical and chemical quality, ecology and quantity) can be taken into consideration. In this manner a more cognitive way of choosing between alternative measures can be obtained. This paper describes an application of such a decision method on a river basin scale. Main topics, in this paper, are the extent to which uncertainties (in technical information and deficiencies in the techniques applied) limit the usefulness of these methods, and also the question whether these techniques can really be used to select measures that give maximum environmental benefit for minimum cost. It is shown that the influence of these restrictions on the validity of the outcome of the decision methods can be profound. Using these results, improvement of the methods can be realised.
\end{abstract}

\section{KEYWORDS}

Integrated water management; river basin management; multiobjective decision-making; uncertainty; cost-effectiveness.

\section{INTRODUCTION}

Since the introduction of the 'Third national policy document on water management' in The Netherlands, there has been a growing interest for the integrated approach to water management issues (Ministry of Transport, Public Works and Water Management, 1989). Both internal integration between different aspects of water management; such as waste water treatment, flood control and groundwater management - as well as external integration between water management and related policy fields, such as environmental and physical planning - are indispensable to the effectiveness of water policies. However, an integrated approach can lead to an increase in complexity in the decision-making process.

In order to cope with this growing complexity, a systematic approach to decision-making is necessary. This systematic approach consists of a rational way of selecting those alternative measures that best meet the objectives of integrated water management. 
In this paper an application of an analytical evaluation method is given, and its practicability is examined. Attention is paid to the question whether uncertainties in input data and deficiencies in the decision-techniques limit the applicability of these methods.

Here, a decision method is applied on a region in the south-west of The Netherlands, in the western part of the province of North-Brabant (see Fig. 1.). The region is situated between the cities of Antwerp and Rotterdam and covers an area of approximately 165.000 hectares. The region has strong industrial and agricultural sectors, but there are also quite extensive nature areas. The main rivers in the region are the Mark and Vliet. Water management in this region is characterised by three major issues (Water authority West-Brabant, 1992). In short, these issues are as follows:

- Water quality

Water quality often does not meet the physical, chemical and ecological standards.

Lowering of groundwater tables

Due to a large number of reasons, among which excessive groundwater extraction and insufficient retention of surface water, lowering of groundwater tables has occurred in the south of WestBrabant. In particular nature areas are affected.

- $\quad$ Sediment contamination

River bed sediments in this region are often polluted with heavy metals and polycyclic aromatic hydrocarbons (PAH's). Because of this, storage of dredged material is subject to very strict conditions with respect to its isolation, management and control.

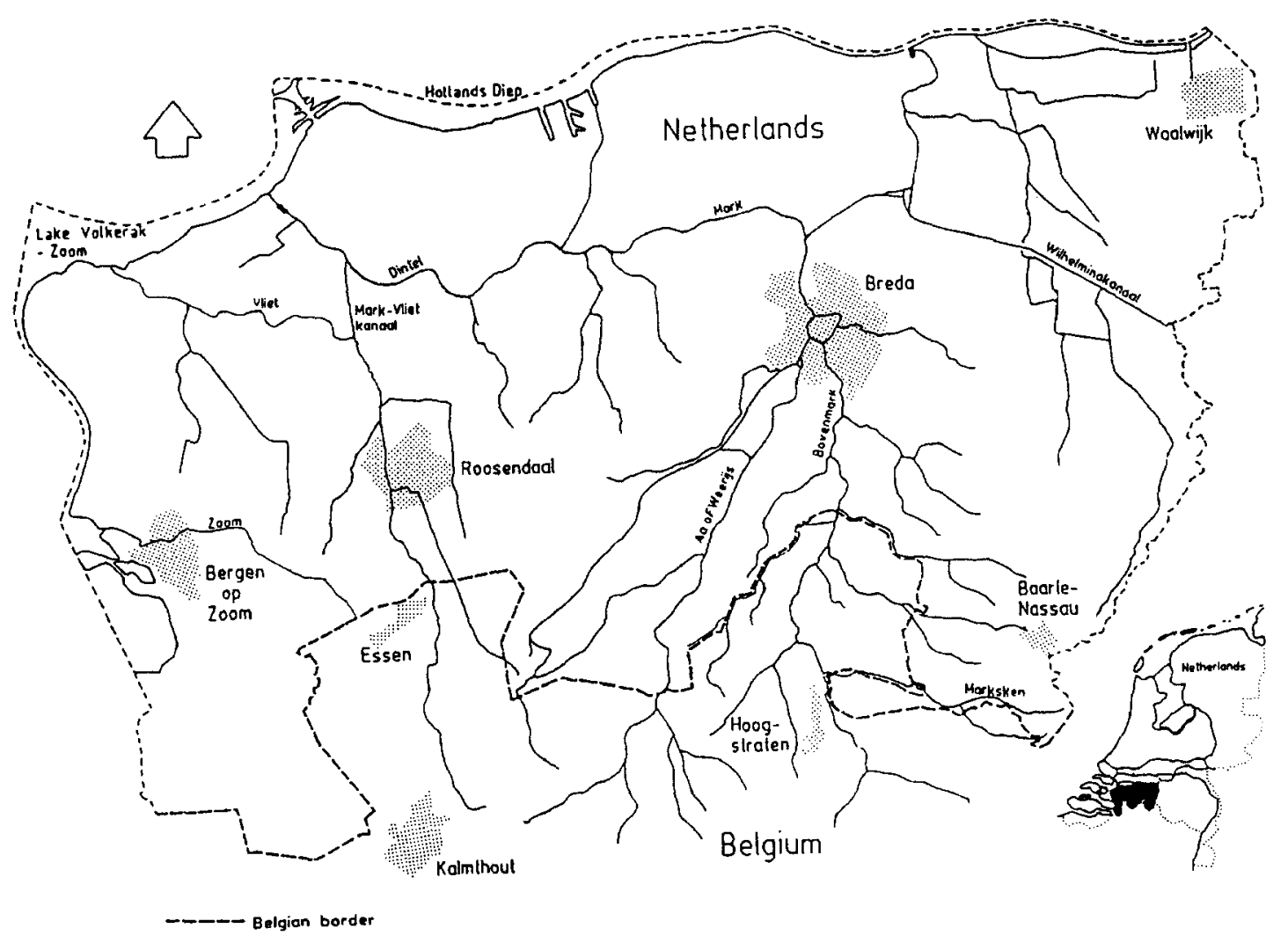

Fig. 1. Map of West-Brabant showing the main cities and rivers

In order to choose among alternative measures, which deal with these problems and other (more traditional) tasks, decisions have to be made. Regarding the diversity of the effects of these measures, a multiobjective decision method could be of use to this problem. 
The process of multiobjective decision-making roughly consists of four steps (Miser and Quade, 1985). First, problems are formulated. Second, to solve the problems, objectives are defined. Thirdly, measures are identified to meet the objectives. In evaluating the effects of the measures, models can be used to predict the consequences of the measures. The effects are translated into criteria. Finally, the measures are compared and ranked.

\section{CRITERIA AND MEASURES}

From the issues 'water quality', 'lowering of ground water tables' and 'sediment contamination', several policy objectives can be derived and translated into criteria.

A. Nutrients in surface water - representing the change in total amount of nutrients in the river (in kilograms), due to the introduction of the measure analysed.

B. Heavy metals in sediments - representing the change in total amount of heavy metals in the sediments (in grams), due to the introduction of the measure analyzed.

C. Polycyclic aromatic hydrocarbons in sediments - representing the change in total amount of PAH's in the sediments (in grams), due to the introduction of the measure analysed.

D. Physical aspects of renaturalisation - representing the effects of a measure on the cross-sectional area of a river and the structure of the riverbanks, measured in qualitative units (positive/negative contribution to renaturalisation).

These criteria are completed with two extra criteria. A first criterion follows the water authorities' traditional tasks: drainage and water distribution. A second criterion represents the water authorities' objective to limit the external costs of the measure, i.e. the financial contribution of third party participants to the costs of the measure. Hence, these criteria can be formulated as:

E. Water supply for use in agriculture, shipping, recreation and industry - representing the change in the amount in cubic meters of water available to the user, due to the implementation of a measure.

F. Financial consequences of the measure for participants - representing the external monetary effects of a measure, in million guilders.

The possible measures were derived from the water management plans of the various local, regional and national water authorities. Measures that can be introduced in the near future were also taken into consideration. The number of measures was reduced in two ways. Measures that show similarity were combined to one measure. Secondly, measures that are not likely to be effective were not included. This resulted in the following measures to be analysed:

1. Upgrading waste water treatment plants - increasing the average phosphate reduction from $60 \%$ to $75 \%$.

2. Dredging - removing $220.000 \mathrm{~m}^{3}$ of sludge from the river Mark.

3. Intensifying control on pollution by industries - intensifying the control on permits to dispose industrial waste water.

4. Renaturalisation of streams and rivers - remeandering streams and rivers and rehabilitation of natural riverbanks

5. Bio-filters - planting of reed vegetation to increase nutrient uptake from surface water.

6. Water-level control - optimising water-levels to land use.

7. Water supply measures for agricultural use - supplying agricultural areas with fresh water in periods of aridity.

8. Alternative maintenance measures - maintenance of riverbank vegetation according to the latest environmental standards.

9. Replacing leaching bank protection - removing bank protection containing phosphate slag and creosote treated wood

10. Reduction of non-point sources in agriculture - reducing pollution caused by the use of fertilizers and pesticides in agriculture.

11. Improvement of sewage systems - building storage reservoirs near sewage overflows. 


\section{THE APPLIED METHOD}

In order to analyze the effects, data were collected on the cost-effectiveness of the measures, represented as effect scores in an impact matrix (Table 1). The effect scores of the various measures consist of two components: a physical, chemical or ecological component and a cost component. The dimension of these effect scores are made up of physical units (kilograms, grams, cubic meters) and a monetary unit (1,000 Dfl.). To determine the effect scores, data were collected in two ways. For measures evaluated in a previous stage of the policy making process, actual research data were used, such as information from sediment-transport models and pilot-studies with bio-filters. These data are assumed to be reliable. Data on the effects of new measures were collected through expert-opinions. Since these data are merely based on estimations of the real effects and costs of the measure, they are less reliable. The discrepancy between the actual and predicted effects can be considerable, due to unintended attitudes, expectations, motives and perceptions of the expert (Cook and Campbell, 1979). Therefore these effects were subject to more thorough (sensitivity) analysis, where uncertainties were determined by defining the limits of an effect score (minimum and maximum value), and were implemented in the impact matrix.

Table 1. Impact matrix

\begin{tabular}{|c|c|c|c|c|c|c|c|}
\hline & & Criteria & & & & & \\
\hline & $\begin{array}{l}\text { Measures } \\
\text { (effect per } 1,000 \\
\text { Dfl. spent) }\end{array}$ & $\begin{array}{l}\text { Nutrients } \\
{[\mathrm{kg}]}\end{array}$ & $\begin{array}{l}\text { Heavy } \\
\text { metals } \\
{[\mathrm{g}]}\end{array}$ & $\begin{array}{l}\text { PAH's } \\
{[\mathrm{g}]}\end{array}$ & $\begin{array}{l}\text { Abiotic } \\
\text { aspects of } \\
\text { renatural. } \\
{[--1++]}\end{array}$ & $\begin{array}{l}\text { Water } \\
\text { supply } \\
{\left[\mathrm{m}^{3}\right]}\end{array}$ & $\begin{array}{l}\text { External costs } \\
\text { [Dfl.mln.] }\end{array}$ \\
\hline 1 & $\begin{array}{l}\text { Upgrading waste } \\
\text { water treatment } \\
\text { plants }\end{array}$ & 39.3 & 52 & 0 & 0 & 0 & 0 \\
\hline 2 & Dredging & 0 & 2947 & 71 & - & 31.44 & 0 \\
\hline 3 & $\begin{array}{l}\text { Intensifying control } \\
\text { on pollutants }\end{array}$ & {$[0 ; 131.2]$} & {$[0 ; 1266]$} & 0 & 0 & 0 & {$[0 ; 50]$} \\
\hline 4 & $\begin{array}{l}\text { Renaturalisation of } \\
\text { streams and rivers }\end{array}$ & 0 & 0 & 0 & ++ & 0 & 0 \\
\hline 5 & Bio-filters & 7.5 & {$[7 ; 21]$} & 0 & - & 0 & 0 \\
\hline 6 & Water-level control & 0 & 0 & 0 & + & 0 & {$[14.78 ; 56.32]$} \\
\hline 7 & $\begin{array}{l}\text { Water supply } \\
\text { measures for } \\
\text { agricultural use }\end{array}$ & 0 & 0 & 0 & 0 & 150.13 & 0 \\
\hline 8 & $\begin{array}{l}\text { Alternative main- } \\
\text { tenance measures }\end{array}$ & {$[0 ; 102.8]$} & 0 & 0 & + & 0 & 0 \\
\hline 9 & $\begin{array}{l}\text { Replacing leaching } \\
\text { bank protection }\end{array}$ & {$[0 ; 14.6]$} & 0 & {$[0 ; 7]$} & 0 & 0 & 0 \\
\hline 10 & $\begin{array}{l}\text { Reducing non-point } \\
\text { sources in } \\
\text { agriculture }\end{array}$ & {$[38.5 ; 57.7]$} & 0 & 0 & 0 & 0 & 7.61 \\
\hline 11 & $\begin{array}{l}\text { Improvement of } \\
\text { sewage system }\end{array}$ & {$[1.5 ; 2.3]$} & 8 & 0 & 0 & 0 & 0 \\
\hline
\end{tabular}

Example: the effect of measure 2 on criterion 2 (2947) means that when spending 1,000 Dfl. on dredging, 2947 grams of heavy metals will be removed. 
By means of weighted summation (Nijkamp et al., 1990) a ranking of the measures can now be calculated. This is achieved by assigning a weight to each criterion. These weights are based on the various interest groups, whose goals are likely to be affected by the implementation of the proposed water management plan. In this case, weights were quantified by asking these participants to rank the criteria according to their personal interests. The following steps were then taken to calculate a ranking of the measures (Janssen, 1992):

1. For each measure $i(\mathrm{i}=1, \ldots, \mathrm{I})$ and criterion $j(\mathrm{j}=1, \ldots, \mathrm{J})$ the effect $p_{j i}$ was measured. This is shown in Table 1. The impact matrix $P$ thus consists of various vectors $P_{i}$ containing the effect scores of measure $i$ on the criteria. Where uncertainty existed about the actual impact of a measure, a range of an expected minimum and maximum score was presented between brackets.

2. To achieve a ranking of the measures, the impact matrix had to be standardised in order to compare the diverse effects. Each score $p_{j i}$ was transformed into a dimensionless unit $v_{j}\left(p_{j j}\right)$. This was done by dividing the effect score by the maximum effect on the specific criterion.

3. Next, preferences of the policy-maker and other participants were translated into weight vectors $\underline{w}$, in which $w_{j}$ represents the relative weight of criterion $j$.

4. The total priority value of a measure $V\left(P_{i}\right)$ was obtained by multiplying the standardised effect score by the weight vector (weighted summation):

$$
V\left(P_{i}\right)=\sum_{j=1} w_{j} v_{j}\left(p_{j i}\right)
$$

5. Finally, this algorithm is repeated for each weight vector.

Using this framework, a ranking was calculated. At first, this was done without weighing the criteria in order to gain greater insight in the influence of the uncertain expert opinions. With a modest simulation computer programme the following results were calculated.

Table 2 . Total priority value and ranking (unweighed)

\begin{tabular}{l|rr|rr}
\hline Measure & $\begin{array}{r}\text { Total priority value } V(P) \\
\text { standard } \\
\text { average } \\
\text { deviation }\end{array}$ & Ranking & $\begin{array}{r}\text { ranking } \\
\text { maximum- } \\
\text { minimum }\end{array}$ \\
\hline 1.Upgrading waste water treatment plants & 0.054 & 0 & 6 & $5-6$ \\
2.Dredging & 0.291 & 0 & 1 & $1-1$ \\
3.Intensifying control on pollutants & 0.120 & 0.076 & 5 & $2-10$ \\
4.Renaturalisation of streams and rivers & 0.170 & 0 & 2 & $2-4$ \\
5.Bio-filters & -0.074 & 0 & 11 & $10-11$ \\
6.Water-level control & -0.022 & 0.051 & 10 & $6-11$ \\
7.Water supply measures for agricultural use & 0.170 & 0 & 2 & $2-4$ \\
8.Alternative maintenance measures & 0.152 & 0.054 & 4 & $2-5$ \\
9.Replacing leaching bank protection & 0.010 & 0.008 & 8 & $7-10$ \\
10.Reduction of non-point sources & 0.039 & 0.010 & 7 & $6-8$ \\
11.Improvement of sewage systems & 0.003 & 0 & 9 & $7-10$ \\
\hline
\end{tabular}


The results show that the influence of the uncertainties on the ranking is profound. Based on these results it is difficult to draw any conclusions regarding the ranking of sensitive measures such as 'intensifying control on pollutants' and 'water-level control'. The large dispersion of these rankings is a result of the uncertainties in the effect scores. However, by classifying categories of rank numbers, some tendencies towards an overall evaluation of measures can be identified. This is shown in Table 3 .

Table 3. Classification of measures according to priority (unweighed)

\begin{tabular}{|c|c|c|c|}
\hline & High Ranking & Average Ranking & Low Ranking \\
\hline Measures & $\begin{array}{l}\text { - dredging } \\
\text { - renaturalisation } \\
\text { - water supply measures } \\
\text { - alternative } \\
\text { maintenance measures }\end{array}$ & $\begin{array}{l}\text { - upgrading waste water } \\
\text { treatment plants } \\
\text { - intensifying control } \\
\text { pollutants } \\
\text { - reduction non-point sources }\end{array}$ & $\begin{array}{l}\text { - bio-filters } \\
\text { - water-level control } \\
\text { - replacing leaching bank } \\
\text { protection } \\
\text { - improvement of sewage } \\
\text { system }\end{array}$ \\
\hline
\end{tabular}

High ranking: largest share of distribution in rank numbers $1,2,3$ or 4 .

Average ranking: largest share of distribution in rank numbers 5,6 , or 7 .

Low ranking: largest share of distribution in rank numbers $8,9,10$ or 11 .

This classification shows some discrepancies with the water authorities' actual policy. Especially the high ranking of 'dredging' and the low ranking of the measure 'improvement of sewage system' is not entirely conform the current efforts of the water manager.

The ranking was achieved without weighing the criteria. Ranking based on the weight vectors showed no vital changes in the outcome of the method. The influence of weighing did only occur when vectors were compared which represented conflicting interests, such as agriculture versus environment. In general there was no significant effect on the ranking.

\section{DISCUSSION AND CONCLUSION}

After achieving this ranking, several questions remained, such as: 'Did the method really reduce complexity?', since one has to put extra effort in sensitivity analysis to gain real insight in the effect of measures; 'Did the achieved ranking result in a maximum environmental benefit at minimum costs?', as no attention was paid to the effects of the measures in time; and 'How can a new policy plan be formulated based on this ranking?', as besides ranking measures to priority, other aspects, such as coping with obligatory measures, extra budgetary margins and larger numbers of measures need to be considered (Witter, et al., 1993).

These questions, together with the results of the method, lead to the following conclusions:

a. The use of a multiobjective decision-method, based on the cost-effectiveness of measures and a sensitivity analysis, leads to a classification of measures.

b. The preferences of participants to certain criteria did not influence the priority setting in the example presented.

c. Improvement in the prediction of the ranking of the measures requires better understanding of the cost-effectiveness of certain measures.

d. Sensitivity analysis is a powerful tool to identify measures of which the cost-effectiveness is too uncertain.

e. For the development of water management plans, it is required to include additional options in the priority setting, such as obligatory measures, extra budgetary margins and time-related effects. 
A final conclusion therefore should be that multiobjective decision methods can be a support to formulate water management plans, but can only be used at their full potential if all of the above- mentioned shortcomings are incorporated in the methods. Further research is necessary to let multiobjective decision-making play a more supportive role in integrated water management.

It should, however, be mentioned that the application of any multiobjective decision method is already a gain in the systematic approach to decision making.

\section{REFERENCES}

Cook, T.D. and D.T Campbell (1979). Quasi-experimentation, design \& analysis issues for field settings. Rand McNally, Chicago.

Janssen, R. (1992). Multiobjective decision support for environmental management. Kluwer Academic Publishers, Dordrecht.

Ministry of Transport, Public Works and Water management (1989). Third National policy document on water management, A time for action. SDU, The Hague.

Miser, H.J. and E.S. Quade (1985). Handbook of systems analysis. North Holland, New York.

Nijkamp P., P. Rietveld and H. Voogd (1990). Multicriteria evaluation in physical planning. North Holland, Amsterdam.

Water authority West-Brabant (1992). Integrated water management plan West-Brabant 1993-1996. HWB, Breda.

Witter, J.V., R. den Engelse and J. J. Bogardi (1993). Optimal integrated water management: a quantitative approach. 